\title{
CONTRIBUIÇÕES DO MACROMARKETING PARA A FORMAÇÃO DE ADMINISTRADORES - PODEMOS MELHORAR O ENSINO DE MARKETING EM CURSOS DE GRADUAÇÃO EM ADMINISTRAÇÃO?
}

\author{
CONTRIBUTIONS FROM MACROMARKETING FOR TRAINING MANAGERS - \\ CAN WE IMPROVE MARKETING EDUCATION IN UNDERGRADUATE BUSINESS
}

ADMINISTRATION COURSES?

Recebido em: $30 / 05 / 2017$ Aprovado em: $26 / 07 / 2017$
Avaliado pelo sistema double blind review
Editora Científica: Claudia Stadtlober
DOI 10.13058/raep.2017.v18n3.628

\begin{abstract}
RODOLFO PERES BERARDINELLI $r$ _berardinelli@yahoo.com.br JOÃO FELIPE RAMMELT SAUERBRONN
\end{abstract}

\author{
UNIVERSIDADE DO GRANDE RIO
}

\section{RESUMO}

A formação dos estudantes de administração no Brasil encontra-se centrada em aspectos gerenciais do marketing e, por conta disso, gestores parecem incapazes de lidar com a complexidade do sistema de trocas. Em um mundo no qual as vidas das pessoas passam a ser cada vez mais afetadas por mercados, torna-se fundamental ampliar a compreensão a respeito da disciplina que trata das relações entre mercados e sociedade: o macromarketing. No presente artigo, realizamos entrevistas em profundidade com nove professores de marketing de cursos de graduação de administração com o intuito de levantar suas visões acerca do ensino da disciplina, das suas lacunas, assim como seus entendimentos a respeito do macromarketing, seus conceitos e suas possíveis contribuições para a formação de futuros administradores. Os dados coletados trouxeram à tona três lacunas do ensino de marketing associadas à superficialidade de tratamento do conceito de mercado, à desconexão da disciplina com questões sociais e perspectivas locais e à visão acrítica do campo. As entrevistas, também, mostraram as potenciais contribuições do macromarketing para a melhoria da formação dos administradores por meio da inclusão de discussões sobre os sistemas de marketing, as consequências sociais do marketing e uma abordagem mais crítica da disciplina.

Palavras-Chave: Ensino de Administração. Ensino de Marketing. Macromarketing. Formação do Administrador

\begin{abstract}
Undergraduate education for Business Administration students in Brazil is found to be strictly focused on managerial aspects of marketing. Because of this, many managers seem to be unable to deal with the complexity of the exchange system. In a world in which markets are increasingly affecting people's lives, it becomes essential to broaden the understanding of the discipline that deals with the relationships between markets and society: macromarketing. In the present paper, we have collected data through in-depth interviews with nine marketing professors of Business Administration undergraduate courses in order to present their visions about the teaching of the discipline and its gaps, as well as their understandings of macromarketing, its concepts and possible contributions to the training of future managers. The data allowed us to identify three gaps in marketing education, related to the superficiality of the treatment of the market concept, the discipline's disconnection from social issues and local perspectives, and an uncritical view of the field. The interviews also brought potential contributions from macromarketing to improving the education of administrators through the inclusion of discussions on marketing systems, social consequences of marketing and a more critical view of the discipline. Keywords: Management Education. Marketing Education. Macromarketing. Manager's Training.
\end{abstract}




\section{INTRODUÇÃO}

O aumento da quantidade de cursos de graduação em administração no Brasil e do número de alunos matriculados nesses cursos foi muito expressivo nos últimos 15 anos, mas isso não significou a melhoria da qualidade da formação do administrador (OLIVEIRA; LOURENÇO; CASTRO, 2015; OLIVEIRA; SAUERBRONN, 2007). Assim, não é surpreendente que a comunidade científica tenha passado a demonstrar preocupação crescente com a educação de administradores no país e tenha produzido uma quantidade expressiva de trabalhos que refletem seu interesse pela temática do ensino (LOURENÇO; TONELLI; MAFRA, 2012). Consequentemente, têm sido cada vez mais frequentes as discussões a respeito do ensino de disciplinas de cursos de graduação em administração, como empreendedorismo (SOUZA; SARAIVA, 2010), gestão de operações (GRAEML; PEINADO, 2013), contabilidade (BORGES; MAFRA, 2013), macroeconomia (BEHRENS, 2013), gestão de projetos (SCHMITZ et al., 2015) e finanças (RODRIGUES; MATIAS, 2016).

O ensino da disciplina de marketing ${ }^{1}$ em cursos de administração, também, tem despertado o interesse de pesquisadores brasileiros tanto a respeito de sua trajetória histórica (BACELLAR; IKEDA, 2011; BOSCHI; BARROS; SAUERBRONN, 2016) quanto sobre as experiências docentes (CASOTTI, 1995; BACELLAR; IKEDA; ÂNGELO, 2005). De forma geral, esses estudos apontam a orientação eminentemente gerencialista da disciplina no Brasil e um foco exclusivamente centrado nas relações entre produtores e consumidores. Tal viés faz com que os cursos de marketing que compõem os currículos de graduação em administração no Brasil sejam caracterizados por uma abordagem essencialmente passiva frente aos fatos sociais e desconsiderem as interações de marketing e sociedade. Esse posicionamento gera um incômodo para parte dos docentes da disciplina, principalmente, para aqueles que se aproximam da perspectiva do macromarketing.

1 A disciplina de marketing, também, pode ser denominada mercadologia ou administração mercadológica em cursos de administração brasileiros. De modo geral, as diferentes denominações não trazem alterações nos conteúdos lecionados. 
A perspectiva do macromarketing trata das relações sistêmicas entre os diversos agentes de mercado e dos impactos desse sistema na sociedade e da sociedade no marketing, em contraposição a um posicionamento alinhado ao micromarketing, que se ocupa de comportamentos e características de agentes individuais como empresas e consumidores (BAGOZZI, 1977; HUNT, 1977). Desse modo, o objetivo do presente trabalho é explorar as impressões de professores de marketing de cursos de administração acerca da disciplina lecionada na graduação e avaliar possíveis contribuições do macromarketing para a formação de administradores.

Este artigo segue esta introdução com uma breve contextualização a respeito do ensino de administração no Brasil, que mostra o descompasso entre as necessidades do mercado e da sociedade e a formação do administrador. Em seguida, trata-se da perspectiva do macromarketing e do ensino da disciplina de marketing em cursos de graduação. Os procedimentos metodológicos são apresentados na quarta seção do trabalho e são seguidos pela análise das entrevistas e discussão. Por fim, discriminam-se as lacunas no ensino de marketing para os cursos de administração e as contribuições do macromarketing para a formação dos administradores, conforme analisado nas entrevistas coletadas, dessa forma, visando motivar mais professores e pesquisadores de marketing a utilizarem e desenvolverem conhecimento de macromarketing em seu contexto de trabalho ou estudo. 


\section{CONTEXTUALIZAÇÃO DO ENSINO DOS CURSOS DE GRADUAÇÃO EM ADMINISTRAÇÃO NO BRASIL}

O ensino de administração no Brasil é marcado pela transferência de conteúdos desenvolvidos fora do país desde sua origem (BARROS; CARRIERI, 2013; BOSCHI; BARROS; SAUERBRONN, 2016). Segundo Barros (2017), a chegada da família real portuguesa ao Rio de Janeiro, em 1808, trouxe impactos sobre a economia local e tornou necessária a preparação de profissionais capacitados a atuarem em atividades comerciais. Assim, a Aula de Comércio, criada durante a reforma do ensino realizada pelo Marques do Pombal, foi instituída no Brasil em 1811 (MENDONÇA, 1982) e promoveu uma formação eminentemente contábil e com foco no controle (LISBOA, 1950). A formação do profissional proposta pela Aula de Comércio atendia às necessidades da prática mercantilista desenvolvida pela Coroa portuguesa àquele tempo.

As atividades de ensino da Aula de Comércio portuguesa evoluíram para as escolas de comércio da década de 1940, onde se abrigariam os cursos de contabilidade, economia e administração (BARROS, 2017). O desenvolvimento do modelo das escolas de comércio, contudo, foi interrompido pela chegada do modelo estadunidense de administração, no início da década de 1950. Nos moldes das Business Schools norte-americanas, foi fundada, em 1954, a Escola de Administração de Empresas de São Paulo da Fundação Getulio Vargas (EAESP/FGV). Fruto de acordos de cooperação técnico-científica entre os EUA e o Brasil, a EAESP/FGV veio atender à necessidade de se preparar profissionais capazes de ocupar funções executivas nas empresas multinacionais em implantação no país (BOSCHI; BARROS; SAUERBRONN, 2016). Com participação efetiva de professores estrangeiros e envolvendo a preparação de um novo corpo docente treinado nos EUA, a experiência da EAESP difundiu-se no país (BARROS; ALCADIPANI; BERTERO, 2015) e tornou-se referência para o ensino de administração no Brasil até os dias atuais.

O aumento da quantidade de cursos superiores em administração, no Brasil, a partir do final dos anos de 1990, deu-se em um ambiente pro- 
fundamente influenciado por interesses mercantis que suplantaram preocupações acadêmicas. Como resultado, conteúdos fragmentados e formação desestruturada afastaram ensino e pesquisa do mundo profissional (OLIVEIRA; SAUERBRONN, 2007).

A crescente complexidade das relações entre mercados e sociedade parece não ser acompanhada pelas escolas de administração, que acabam formando profissionais ainda não plenamente capacitados. Tal fato ganha contornos mais preocupantes quando se nota a falta de contato entre o conteúdo lecionado e a realidade local, em função da simples replicação de conteúdos e processos pedagógicos importados pelas escolas de administração brasileiras (VASCONCELOS; COSTA; CARVALHO, 2016). Enquanto coordenadores dos cursos de graduação em administração continuam discutindo os currículos a partir da ordenação das matérias que os compõem, observa-se divisão e fragmentação do conhecimento, como já apontado por Nicolini (2003). Em alguns casos, os cursos de graduação passaram a ter como objetivo primordial a preparação dos alunos para o Exame Nacional de Desempenho dos Estudantes (ENADE), o que também colabora para o afastamento das escolas de administração do ambiente no qual estão inseridas e, eventualmente, incentiva a reprodução de conhecimento importado e consolidado.

Há uma evidente necessidade de se repensar o processo de formação do administrador no Brasil diante das exigências da sociedade e do mercado de trabalho (OLIVEIRA; LOURENÇO; CASTRO, 2015). Aktouf (2005) destaca que o conteúdo de formação do profissional de administração deveria unir técnica a objetivos sociais e desenvolver uma visão coletiva e comunitária. O administrador, portanto, deveria ser preparado para ser capaz de compreender criticamente interesses do capital, necessidades de trabalhadores, alertas de ambientalistas e demais pressões de stakeholders, de forma a tomar decisões gerenciais mais conscientes (LOURENÇO; TONELLI; MAFRA, 2009).

Em que pese a falta de discussões mais profundas a respeito do papel da disciplina de mercadologia na formação de administradores, essa parece cumprir um papel importante nesse processo. Há de se notar certo 
isolamento da disciplina de marketing frente às demais, talvez, em função de sua suposta autossubsistência tanto no mercado profissional quanto na academia, ou por ser compreendida como uma disciplina incapaz de percepção crítica e unicamente voltada para a instrumentalização da geração do lucro das empresas (SAUERBRONN, 2013). 


\section{A DICOTOMIA MACROMARKETING VERSUS MICROMARKETING E O ENSINO DA DISCIPLINA DE MARKETING}

É curioso notar que o conhecimento de marketing trata, em menor ou maior profundidade, dos aspectos societais das atividades de mercado desde suas origens. Tal perspectiva já era evidente na obra de Alderson (1957), que, até os dias atuais, influencia o pensamento em macromarketing e é, frequentemente, revisitada (WOOLISCROFT; TAMILIA; SHAPIRO, 2006; TADAJEWSKI, 2009; SHAW, 2010). Segundo Hunt e Burnett (1977), a temática sempre esteve presente na disciplina, mas a denominação macromarketing só surgiu a partir da década de 1970. Naquele momento, era necessário que as discussões a respeito de aspectos societais do marketing ganhassem corpo frente à ascensão de abordagens centradas em aspectos mais operacionais da atividade de marketing, tanto na pesquisa quanto no ensino da disciplina.

Com o entendimento de que era necessário consolidar o macromarketing, alguns acadêmicos apresentaram suas perspectivas acerca desse subcampo. Para Shapiro (1973), o macromarketing está associado a uma abordagem da atividade econômica agregada que visa atender aos objetivos da sociedade por meio de um eficiente fluxo de bens e serviços. Assim, pode-se dizer que o micromarketing é orientado para a firma, enquanto o macromarketing estuda o marketing no contexto do sistema econômico como um todo, com ênfase na sua performance agregada (MOYER, 1974). A obra de Moyer (1974), publicada originalmente em 1972, foi o primeiro livro-texto dedicado ao macromarketing e trouxe a primeira apresentação da distinção entre macromarketing e micromarketing. O autor destacou os critérios de agregação e desempenho, desse modo, caracterizando a visão mais ampla e sistêmica do macromarketing, e deu ênfase à avaliação normativa do papel do marketing na sociedade.

Shelby Hunt, acadêmico que sempre se preocupou com as delimitações teóricas e epistemológicas da disciplina de marketing, apontou o impacto e as consequências da sociedade sobre os sistemas de marketing como característica dos estudos de macromarketing (HUNT, 1977). Além 
disso, propôs que o macromarketing se referiria ao estudo de sistemas de marketing e ao impacto e às consequências dos sistemas de marketing na sociedade, enquanto o micromarketing trataria do estudo de atividades de marketing de unidades individuais, como organizações, firmas, consumidores e famílias (HUNT, 1977).

O entendimento do micromarketing como dedicado à compreensão dos comportamentos de agentes individuais e das relações didáticas entre atores de marketing é reforçado por Bagozzi (1977). O autor considerou que o macromarketing se caracteriza pelo estudo de redes de relacionamento que conectam integrantes do marketing e padrões sociais ou relações sistemáticas entre agentes de marketing (BAGOZZI, 1977). White e Emery (1978) caracterizaram o macromarketing como o estudo dos impactos das transações por meio da análise de um amplo sistema, que inclui a sociedade e o Estado (no papel de regulador) e, dessa forma, o conceito de sistemas de marketing (ou sistemas de mercado) tornou-se central para o campo do macromarketing.

Dixon (1984) identificou o sistema de marketing como um importante e diferenciado subsistema da sociedade, tendo impacto e sendo impactado por outros sistemas sociais, culturais e ambientais. Enquanto os resultados de uma troca são as vendas, o resultado final de um sistema de marketing é a capacidade de um sortimento de produtos e serviços comercializados contribuir para o bem-estar (LAYTON, 2007). Ancorado no conceito de sistema de marketing, o macromarketing desenvolveu-se como o estudo do complexo processo de concepção, coordenação e controle do crescimento e da evolução dos sistemas de marketing (MEADE; NASON, 1991). Layton (2007) destacou o foco do macromarketing na geração de bem-estar e definiu o sistema de marketing como:

Uma rede de indivíduos, grupos ou entidades ligadas direta ou indiretamente, por meio de participações sequenciais ou compartilhadas em trocas econômicas que criam, constituem, transformam e tornam disponíveis sortimentos de produtos tangíveis ou intangíveis em resposta às demandas dos consumidores. (LAYTON, 2007, p. 230). 
O estudo dos sistemas de marketing e dos relacionamentos de troca a partir de uma perspectiva que leva em consideração as consequências do marketing na sociedade e da sociedade no marketing é a característica principal do macromarketing. Para o macromarketing, são os sistemas de marketing, e não as unidades produtoras, que permitem que as trocas aconteçam nos mercados (DIXON, 1984; LAYTON, 2007; SHAPIRO, 2012). O Quadro 1, apresentado a seguir, traz um resumo dos entendimentos a respeito do macromarketing levantados neste trabalho.

Quadro 1 Resumo dos entendimentos a respeito do Macromarketing

\begin{tabular}{|c|c|}
\hline & \\
\hline $\begin{array}{l}\text { Shapiro } \\
(1973)\end{array}$ & $\begin{array}{c}\text { Campo do marketing com uma visão geral da atividade } \\
\text { econômica agregada, visando aos objetivos da sociedade } \\
\text { por meio de um eficiente fluxo de bens e serviços. }\end{array}$ \\
\hline $\begin{array}{l}\text { Moyer } \\
(1974)\end{array}$ & $\begin{array}{l}\text { Estudo do marketing no contexto do sistema econômico } \\
\text { como um todo, com ênfase na sua performance agregada. }\end{array}$ \\
\hline Hunt (1977) & $\begin{array}{c}\text { Campo do marketing que estuda os sistemas de } \\
\text { marketing, seus impactos e suas consequências sobre a } \\
\text { sociedade e os impactos e consequências da sociedade } \\
\text { sobre esses sistemas. }\end{array}$ \\
\hline $\begin{array}{l}\text { Bagozzi } \\
(1977)\end{array}$ & $\begin{array}{l}\text { Estudo de redes de relacionamento que conectam } \\
\text { integrantes do marketing e padrões sociais ou relações } \\
\text { sistemáticas entre agentes de marketing. }\end{array}$ \\
\hline $\begin{array}{l}\text { White e } \\
\text { Emory } \\
(1978)\end{array}$ & $\begin{array}{l}\text { Estudo dos impactos das transações por meio de um } \\
\text { amplo sistema, sociedade ou grupos. }\end{array}$ \\
\hline $\begin{array}{l}\text { Meade } \\
\text { e Nason } \\
(1991)\end{array}$ & $\begin{array}{l}\text { Estudo do complexo processo de coordenação e controle } \\
\text { do crescimento, evolução e concepção dos sistemas de } \\
\text { marketing. }\end{array}$ \\
\hline $\begin{array}{l}\text { Layton } \\
(2007)\end{array}$ & $\begin{array}{l}\text { Disciplina cujo principal pilar é o sistema de marketing, } \\
\text { que se fundamenta em um conceito social voltado para a } \\
\text { comunidade, no compartilhamento e no ganho de todos } \\
\text { os atores envolvidos. }\end{array}$ \\
\hline
\end{tabular}


Apesar do desenvolvimento de um corpo de conhecimento consistente e relevante, o macromarketing permaneceu restrito ao ambiente acadêmico e não passou a fazer parte da formação de profissionais de administração e marketing. No tocante ao ensino de mercadologia, essa ausência deve-se à ascensão da perspectiva gerencial a partir da década de 1960, que ofuscou as demais escolas de pensamento de marketing (SHETH; GARDNER; GARRETT, 1988). O conhecimento do campo passou a ser conformado por práticas de marketing, como segmentação de mercados e gestão do composto mercadológico, e não assimilou a discussão a respeito dos aspectos societais do marketing e as relações entre mercados e sociedade. Posteriormente, a consolidação da perspectiva da escola do comportamento do consumidor (SHETH; GARDNER; GARRETT, 1988) reforçou o foco nas unidades individuais do mercado e afastou ainda mais outras concepções de estudos dos mercados dos temas ensinados na disciplina. Como apontam Tamilia e Veilleux (2007), os estudantes de graduação têm a impressão de que marketing é meramente uma ferramenta que pode ser usada por empresas, organizações sem fins lucrativos e governos.

A opção de ensino da disciplina baseada na perspectiva do micromarketing parece estar relacionada às demandas do mercado do trabalho, mas deixa de lado importantes temas frente aos quais o administrador deparar-se-á em sua trajetória profissional. Fleming et al. (2015) chegam a afirmar que discussões a respeito do sistema de marketing estavam presentes em edições mais antigas de livros-texto da disciplina, mas não em suas versões mais atuais, onde abriram espaço para discussões mais esmiuçadas de temas em voga a cada momento (marketing de relacionamento, marketing de serviços, branding, etc.). Segundo os autores, em edições mais recentes, os livros-texto mais utilizados no ensino de mercadologia relacionam sistemas de marketing ao contexto específico dos canais de distribuição ao trataram de sistemas horizontais e verticais de marketing (FLEMING et al., 2015).

Hoje, observamos que matérias fundamentais para o desenvolvimento sustentável de (sistemas de) mercados, como justiça social; políticas públicas e regulação de mercados; marketing e desenvolvimento; consumo 
responsável e sustentável; e marketing e qualidade de vida, são objetos de estudo do macromarketing, mas não fazem parte do conteúdo de marketing apresentado aos alunos de graduação (VASCONCELOS; COSTA; CARVALHO, 2016). O estudante de administração, então, completa seu curso com uma formação eminentemente reduzida a respeito do conhecimento em marketing. 


\section{PROCEDIMENTOS METODOLÓGICOS}

O objetivo deste trabalho foi explorar o ensino de marketing em cursos de graduação em administração e avaliar as possíveis contribuições do ensino de macromarketing para a formação de administradores. Para tanto, foi necessário investigar mais profundamente as experiências de ensino de mercadologia em cursos de graduação em administração e discutir a capacidade de o macromarketing preencher lacunas da formação do administrador.

Os procedimentos metodológicos envolveram a coleta de dados qualitativos com nove professores de marketing de cursos de graduação de administração. Os critérios para seleção desse grupo de docentes foram o de familiaridade com o estudo do macromarketing (verificada a priori) e de acessibilidade, mas foi alcançada uma considerável diversidade de perfis. Com o intuito de manter o anonimato dos respondentes, elaborou-se dois quadros: o Quadro 2 apresenta o perfil dos professores, identificados apenas por números, baseado na formação e no tempo de atuação à frente da disciplina em cursos de graduação de administração, enquanto o Quadro 3 apresenta as listas das instituições de ensino nas quais esses professores obtiveram o maior grau (instituições de origem) e das instituições de ensino em que lecionam (instituições de atuação).

Quadro 2 Perfil dos Professores Entrevistados

\begin{tabular}{|c|c|c|}
\multicolumn{1}{|c|}{ Professor } & Grau de Instrução & Tempo Lecionando Marketing \\
\hline 1 & Doutor & 9 anos \\
\hline 2 & Mestre & 8 anos \\
\hline 3 & Doutor & 10 anos \\
\hline 4 & Mestre & 10 anos \\
\hline 5 & Mestre & 25 anos \\
\hline 6 & Doutor & 13 anos \\
\hline 7 & Doutor & 16 anos \\
\hline 8 & Doutor & 24 anos \\
\hline 9 & Doutor & 28 anos \\
\hline
\end{tabular}


Quadro 3 Instituições de origem e de atuação dos Professores entrevistados

\begin{tabular}{|c|c|c|}
\hline \multirow[b]{3}{*}{$\begin{array}{c}\text { Instituição de Origem } \\
\text { (onde obteve maior } \\
\text { grau) }\end{array}$} & EBAPE/FGV RJ & 3 respondentes \\
\hline & COPPEAD/UFRJ & 2 respondentes \\
\hline & $\begin{array}{c}\text { PUC Rio } \\
\text { PUC SP } \\
\text { EAESP/FGV-SP } \\
\text { Unigranrio/RJ }\end{array}$ & 1 respondente cada \\
\hline \multirow[b]{2}{*}{$\begin{array}{l}\text { Instituição de } \\
\text { Atuação }\end{array}$} & $\begin{array}{c}\text { EBAPE/FGV RJ } \\
\text { Unigranrio/RJ }\end{array}$ & 2 respondentes cada \\
\hline & $\begin{array}{c}\text { PUC Rio } \\
\text { ESPM RJ } \\
\text { UFPB } \\
\text { UEM } \\
\text { UNESA }\end{array}$ & 1 respondente cada \\
\hline
\end{tabular}

A opção pela coleta de dados qualitativos é compatível com a abordagem exploratória da pesquisa e envolveu entrevistas em profundidade em contatos face a face e entrevistas por e-mail. Essa variedade de estratégias de coleta de dados é justificada pela distância física de dois entrevistados. As entrevistas presenciais tiveram duração média de 50 minutos e foram realizadas nos locais de trabalho dos professores.

Tanto nas interações diretas quanto nas realizadas por correio eletrônico, foi utilizado um roteiro de entrevistas (vide Anexo A) construído com base nas explorações bibliográficas realizadas previamente. O roteiro sofreu algumas alterações à medida que as entrevistas foram acontecendo, de forma que a versão enviada por e-mail a dois professores se apresentou no formato final de desenvolvimento. Ao fim, o roteiro de entrevistas utilizado foi composto de três partes. A primeira parte continha questões relativas à experiência do docente à frente da disciplina de marketing e sobre sua familiaridade com o macromarketing, além de questões que permitissem a definição do perfil do docente. Na segunda parte, o ensino de marketing em si era tratado mais profundamente e o respondente era chamado a re- 
fletir a respeito dos temas comumente abordados na disciplina, do material didático utilizado e dos objetivos da disciplina associados à formação do administrador. A terceira parte era composta por perguntas que exploravam os temas de macromarketing e a visão do docente a respeito desses temas, incluindo possíveis contribuições do macromarketing para o ensino de administração.

As entrevistas foram gravadas, transcritas e tratadas com base no método de análise de conteúdo, seguindo a proposta de Bardin (1977). Assim, o exame dos dados iniciou com a organização e sistematização das ideias apresentadas pelos professores. Em seguida, foi desenvolvida a fase de codificação, quando os dados foram agregados em unidades analíticas e, por fim, foram executadas as inferências a respeito dos dados analisados.

O processo de análise do conteúdo das entrevistas permitiu que fossem reunidas as falas dos professores em conjuntos analíticos, ou categorias, que propiciaram uma exploração a respeito de como os professores enxergavam o ensino de marketing em cursos de graduação em administração e as possíveis contribuições do ensino de macromarketing para a formação de administradores. Trechos das entrevistas são apresentados como suporte à análise e discussão dos dados. 


\section{ANÁLISE DAS ENTREVISTAS E DISCUSSÃO}

\section{VISÃO GERAL DA DISCIPLINA DE MARKETING}

Por considerar que os professores entrevistados são comprometidos com atividades de ensino há algum tempo, o ponto de partida das entrevistas deu-se com a exploração das experiências docentes desses sujeitos frente à disciplina de marketing em cursos de graduação em administração. Inicialmente, foram levantadas as visões acerca da disciplina e sua conexão com outros temas de administração.

(Marketing) é a disciplina que trabalha a tarefa de trocas, inclusive, mas não apenas, sua promoção (...) e as trocas são base do fechamento do ciclo do processo organizacional. Sem trocas não há sentido na ação organizacional, seja qual for o tipo de organização ou agente ofertante. Por esse entendimento, marketing está intimamente conectado com todas as tarefas centrais da eficiência do processo gerencial, que deve ser, ao menos em intenção, a meta dos cursos de administração. (Professor 6)

O Professor 9 destacou a importância do marketing na conexão entre organizações e sociedade:

(...) o marketing vai levar para a empresa essa discussão dos grandes temas, por exemplo: é raro você ver uma questão de sustentabilidade trazida pelo pessoal de finanças, é raro você ter uma discussão acerca de controle de mão de obra escrava pelo pessoal de logística, quem traz esses grandes temas é o marketing, porque é justamente o marketing que vai fazer a conexão entre a atividade empresarial, a sociedade, sua base de clientes e seus consumidores internos.

Pode-se verificar, nas falas desses professores, um olhar mais amplo a respeito da disciplina de marketing e sua relação com a administração. Seus pontos de vista são claramente influenciados pelo conhecimento do macromarketing, o que será explorado com maior rigor mais à frente, mas, aqui, já revelam reflexões importantes com relação à disciplina. 
Ainda em relação à exploração acerca das visões dos professores, os objetivos da disciplina de marketing em cursos de administração, também, mereceram algumas considerações dos professores entrevistados:

Pensando em graduação, depende da vocação do curso. Se administração empresarial, pública, comunicação social, ou publicidade (...) Em geral, entendo que o objetivo é familiarizar o discente com os fundamentos gerais das trocas, econômicas ou não, e com os processos e técnicas do gerenciamento equilibrado das trocas entre ofertantes e demandantes. A especificação, claramente, vai depender da finalidade do curso. Em administração empresarial, por exemplo, a vocação do curso impõe o objetivo de termos uma disciplina orientada a ensinar como promover trocas em favor da empresa. (Professor 6)

Ao entenderem que a disciplina de marketing cumpre um papel importante na formação do administrador, os professores manifestaram desconforto frente aos objetivos da disciplina comumente encontrados em cursos de graduação em administração.

(os objetivos da disciplina de marketing) são enviesados. Acho que a formação que se dá hoje em dia para o estudante de marketing é enviesada, é muito mais uma formação instrumental do que propriamente uma formação voltada para um campo epistemológico. Marketing, assim como a psicologia, é um campo que converge conhecimento de diferentes áreas. O ensino de marketing atual, devido à difusão disso nas escolas, é um ensino ferramental. (Professor 7)

Parte desse desconforto pode-se entender no tocante à maneira como o marketing vem sendo ensinado na graduação em administração ao longo do tempo. Parece haver a consolidação e difusão de uma forma "correta" de se tratar a disciplina, que está refletida nos manuais utilizados e na estrutura da formação do aluno de administração.

Acho (o ensino de marketing) muito concentrado em comunicação, ou seja, eu vejo que o objetivo tem sido ensinar o básico do pensamento de marketing nessa relação de consumo. (Professor 4) 
Tradicionalmente, nós temos um cerceamento do conhecimento de marketing aplicado na graduação nos cursos de administração. Então, minha preocupação é que esse tipo de abordagem acabe resultando numa concepção específica de mercado que é muito limitada diante do que marketing realmente é. (Professor 1)

(...) tinha aula que tinha gente que cursava administração e gente que cursava relações internacionais. E o pessoal de relações internacionais, quando você apresentava marketing e a ideia que marketing tinha de mercado, eles achavam muito raso. E aí, quando você problematizava isso com o ambiente da globalização, de qual o papel do estado, o papel das grandes corporações, do movimento civil..., isso interessava muito mais e era recebido com muito mais sede de conhecer e desafiar coisas novas do que o pessoal de administração. (Professor 2)

O Professor 3 criticou a distribuição dos temas de marketing nos cursos de administração:

Eu diria que a parte referente às estratégias da empresa, estratégias de marketing da empresa, deveria ser uma parte muito menor do que é. Eu diria que não chegaria a $50 \%$, porque não faz o menor sentido você pensar esse universo das estratégias desconsiderando toda a constituição de mercado, todas as práticas de mercado, todos os agentes de mercado.

Ficou claro que a disciplina de marketing é entendida como um componente importante das práticas de gestão, mas que, ao mesmo tempo, o curso de administração não apresenta uma formação muito extensa na matéria. Uma visão mais ampla do marketing poderia levar a disciplina ao interesse de um público maior, mas, também, poderia servir para expandir a formação do administrador em marketing. Essa formação pode ser revista e caminhar para algo mais amplo do que a visão gerencialista, associada ao micromarketing. 


\section{LACUNAS NO ENSINO DE MARKETING NA GRADUAÇÃO EM ADMINIS-} TRAÇÃO

A exploração das experiências docentes deixa claras as lacunas com relação à formação mercadológica do administrador no Brasil. Nesse sentido, levantou-se com os professores três lacunas no ensino de marketing em cursos de administração: pouca compreensão a respeito do conceito de mercado; desconexão entre o conhecimento da disciplina e a sociedade; e falta de visão crítica acerca das atividades de marketing.

A formação em marketing do administrador é considerada insuficiente e a abordagem micro e gerencial tratada nos cursos de graduação é vista como reducionista. Em grande medida, isso ocorre porque a disciplina de marketing não promove aprofundamento da compreensão do aluno a respeito do conceito de mercado. O Professor 1 destacou a importância do entendimento sobre o mercado para o aluno de administração e a consequente relevância do marketing em cumprir esse papel:

Para o aluno, entender o mercado talvez seja uma das coisas mais importantes que ele deva aprender em administração. Porque ele não controla o mercado, ele pode tentar influenciar de alguma forma, mas ele não controla.

No entanto, na composição corrente da disciplina de marketing, não há espaço para a discussão mais profunda acerca do mercado. O professor 2 expressou sua insatisfação com a forma com que o conceito de mercado é tratado no material didático utilizado na formação dos futuros administradores:

(os manuais de marketing utilizados) partem de uma naturalização do que é mercado sem ao menos problematizar. E isso na graduação! Na verdade, essa concepção do que é mercado para a graduação acaba comprometendo muito a própria formação do aluno.

Sem compreender mais profundamente o mercado, o aluno passa a ter contato com as estratégias de marketing de forma desconectada e ape- 
nas processual. O Professor 3 assinalou a importância do conhecimento da constituição de mercado para o ensino de marketing:

Como é que você consegue fazer um curso e dizer que alguém estaria apto tecnicamente a desenhar, estabelecer ou reconhecer táticas e estratégias de marketing empresariais se essa pessoa não consegue ter o mínimo de trânsito em constituição de mercado? Ela não conhece os agentes de mercado, ela não conhece as práticas que podem se estabelecer entre os diferentes agentes...

As considerações dos professores mostraram que o formato corrente de ensino de marketing contribui para uma formação deficiente do administrador. A limitada compreensão a respeito do mercado distancia o curso de administração do ambiente profissional, assim, colaborando para o que Prestes Motta (1983) destacou como incapacidade do administrador em acompanhar as constantes mudanças do meio empresarial.

Além de uma compreensão estreita a respeito do conceito de mercado, os professores entrevistados, também, apontaram que o conteúdo lecionado em marketing em cursos de administração distancia marketing da sociedade. O Professor 6 iniciou essa discussão apontando que a concentração no foco gerencial reduz a compreensão do futuro profissional a respeito do que realmente acontece no mercado:

A visão restrita de marketing o define como "um conjunto de técnicas orientado a contribuir para empresas ganharem mais dinheiro". Caberia ir além dessa visão gerencial e "for business", incluindo elementos da visão dos sistemas de marketing (...) e com aplicações além de organizações empresariais, indo além da visão for business.

Como se verifica, a perspectiva de marketing concentrada na análise da relação entre unidades produtoras e unidades consumidoras e que exclui os demais componentes do mercado é uma lacuna do ensino de marketing em cursos de graduação. 
Marketing conecta empresa com sociedade, nenhuma atividade empresarial vive desconectada da sociedade e me parece que a área que isso mais tem impacto é no marketing, porque nós trabalhamos diretamente com o consumidor e com a sociedade. Ou seja, qualquer mudança econômica, política, social, cultural, de sustentabilidade, tecnológica vai impactar no marketing e, consequentemente, vai impactar no âmbito da atividade empresarial. (Professor 9)

O afastamento entre marketing e sociedade no conteúdo da disciplina é apontado, por Tamilia e Veilleux (2007) e por Fleming et al. (2015), como uma característica dos cursos de graduação contemporâneos. Ao longo do tempo, observou-se a crescente concentração do ensino de marketing em temas da administração de marketing e do comportamento do consumidor e a tendência à compreensão da sociedade como uma "externalidade". No entanto a necessidade de um ensino de marketing que contemple a sociedade é colocada pelos entrevistados e já foi destacada, por Bartels e Jenkins (1977), como uma função de teóricos e educadores de marketing.

A terceira lacuna no ensino de marketing em cursos de graduação de administração apontada pelos professores entrevistados envolve a ausência de uma visão crítica no currículo da disciplina. Esse tema tanto se relaciona à replicação de conceitos limitados (como o conceito de mercado, tratado anteriormente) quanto à falta de um conteúdo mais próximo à realidade do Brasil.

Acho que falta à disciplina de marketing, o que a disciplina de administração e organizações incorporou, porque praticamente qualquer curso de administração hoje tem uma disciplina de estudos críticos, tem uma disciplina de teoria crítica de administração. Eu veria com muito bons olhos uma disciplina crítica de marketing, usando aspectos de macromarketing, e um pouco no modelo da economia, uma disciplina de administração brasileira, ou estudos brasileiros de administração e marketing. (Professor 5)

A perspectiva crítica, contudo, não é vista como incompatível com a abordagem do micromarketing. Os professores apontam para a necessidade de se complementar o conteúdo correntemente ensinado com uma pers- 
pectiva mais ampla a respeito das implicações das atividades de marketing para fora da organização e, assim, provocar no aluno uma visão crítica como consequência. O Professor 8 propôs a conciliação entre os aspectos operacionais do marketing e a reflexão mais ampla a respeito dessas atividades.

Na graduação, acho importante ter o ferramental, algo que eles possam aplicar na empresa e ao mesmo tempo também dar uma visão crítica, para que eles entendam implicações, consequências do marketing na sociedade.

Esses pontos de vista vão ao encontro da posição de Vasconcelos, Costa e Carvalho (2016), que afirmam que reduzir o marketing apenas à visão do micromarketing acaba por limitar a formação crítica e reflexiva do estudante de administração.

\section{RELEVÂNCIA DA DISCIPLINA DE MARKETING NA FORMAÇÃO DE ADMI- NISTRADORES}

As lacunas no ensino de marketing em administração contribuem para a uma diminuição da relevância da disciplina. Os professores entrevistados consideraram que a visão limitada do marketing impacta negativamente na formação dos administradores porque diminui a importância da disciplina para a atividade profissional.

Isso é curioso, porque eu não sei até que ponto marketing pode ser considerado algo estratégico para a organização. Porque, da maneira que ele é apresentado na graduação, ele é extremamente operacional. É um cara que fica na grande empresa rodando tabela de Access para fazer promoção. E ele consegue ser um analista, um gerente, um coordenador ali. Qual a importância desse cara para o posicionamento da empresa no mercado? Aí, eu acho que, para ele, mercado é algo muito reduzido. Ele não sabe jogar, ele não tem ferramentas para jogar esse jogo. (Professor 2)

A crise de relevância do marketing já vem sendo discutida na academia há algum tempo (O’SHAUGHNESSY, 1997; PIERCY, 2002; FARIA; WENSLEY, 2005; SAUERBRONN, 2013), mas não parece ter ainda surtido 
efeitos na educação em marketing. Como não se tem uma percepção mais completa a respeito das funções de marketing dentro do ambiente organizacional, as atividades do administrador são restritas e podem ter efeito negativo para as organizações.

(...) o que mais me desperta a atenção é a redução da noção de marketing à comunicação de marketing. Isso faz com que a prática de marketing seja limitada em seu escopo, o que é ruim para as organizações. (Professor 9)

No tocante à forma como o marketing é visto pela sociedade, os entrevistados apontaram como a visão limitada do marketing acaba por gerar uma generalização negativa com relação às práticas de marketing em organizações. Marketing é entendido como um instrumento de manipulação utilizado para o malefício das pessoas:

Eu acho que, nos últimos anos, com essas denúncias dos "marqueteiros", marketing virou ferramenta do demônio, né? Um corrupto safado. Alguém que mente. Então, acham que é a ferramenta da mentira, alguém tá buscando te manipular, acho que uma pesquisa geral daria alguma coisa parecida com isso. (Professor 5)

A disciplina de marketing acaba sendo considerada como um ponto menos importante na formação do administrador na medida em que é identificada no ambiente organizacional como atividade meramente operacional e/ou movida por interesses escusos. Essa percepção mostra as limitações do formato atual de ensino de marketing na graduação e motiva a discussão a respeito das formas de se aperfeiçoar o ensino da disciplina na graduação em administração.

\section{CONTRIBUIÇÕES DO MACROMARKETING AO ENSINO DE MARKETING}

Frente às lacunas do conhecimento de marketing na formação dos administradores observadas e a crise de relevância da disciplina apresentada pelos professores, as contribuições do macromarketing para o ensino de administração e marketing foram abordadas como algo de fundamental 
importância pelos entrevistados. O Professor 9 apontou na direção de se compreender mais profundamente o mercado:

Dentre os objetivos do ensino de marketing nos cursos de administração no Brasil está a formação de um olhar para as relações entre agentes de mercado. Procurar capacitar pessoas para compreender e desenvolver relações de mercado. Talvez esse fosse um objetivo adequado pelo fato de permitir não só contextualizar, em cada mercado, em cada curso, em cada lócus, quem são os agentes envolvidos, como também a dinâmica dos mesmos.

O Professor 6 relatou uma lista de temas de macromarketing que devem ser incorporados à formação de administradores e destacou o sistema de marketing e a relação de trocas como tópicos essenciais para a formação de profissionais capacitados a atuarem no mercado:

Todos os temas regulares (de macromarketing) são relevantes: conceito e estrutura dos sistemas agregados de marketing, externalidade e regulação de marketing, justiça distributiva e mercados, sistemas de trocas e qualidade de vida. Não vejo prioridade, se houver tempo e espaço para tudo isso. Mas não havendo, os temas essenciais são conceito e estrutura dos sistemas agregados de marketing e visão de equilíbrio e justiça de trocas.

O sistema de marketing é um dos conceitos mais importantes no escopo do macromarketing e contribui para a expansão da compreensão a respeito das complexidades do mercado. Ter a visão do marketing para todo o sistema econômico é o mais relevante aspecto do macromarketing para Moyer (1974). De acordo com Layton e Grossbart (2006), o estudo de um sistema de marketing, frequentemente, envolve temas como canais de marketing, relações de troca e ambiente de marketing.

A contribuição vem no estabelecimento de uma visão de equilíbrio dos sistemas de trocas. Falo de sistemas, na visão de Roger Layton. Além da potencial contribuição das ferramentas de marketing no interesse social, como as práticas de marketing social, marketing de organizações sociais, marketing de lugares... (Professor 6) 
Associada à compreensão dos sistemas de marketing, a relação entre mercados e sociedade também atende ao propósito de reduzir as lacunas no ensino de marketing e aumentar sua relevância na formação dos administradores. O Professor 2 destacou essa contribuição do macromarketing ao fazer a seguinte consideração:

Acho que a gente poderia vencer essa ideia já viciada do que marketing é, e estender a visão do aluno, principalmente da graduação, sobre os efeitos que essas práticas causam ao seu redor. Não é só pensar em lançar um produto com a embalagem biodegradável, não é essa a contribuição do macromarketing, é uma contribuição contínua, que faça com que o aluno pense sobre o que ele faz.

A temática das consequências sociais do marketing amplia não apenas o escopo da disciplina, mas, também, a sua relevância ao aproximar marketing e políticas públicas, como tratado por Nason (1989). Esse tema também foi abordado por professores como uma contribuição do macromarketing à formação dos administradores.

Os impactos sociais e naturais, como a gente está consumindo as riquezas do planeta. E aí, tem que olhar os temas todos do macromarketing: o consumo exagerado das matérias-primas, degradação do meio ambiente, os excluídos desse mercado de consumo, a construção dessa felicidade paradoxal, a formação de uma sociedade acrítica, orientada para o consumo. (Professor 5)

Shapiro (2006), também, destacou questões como sustentabilidade, consumo, políticas públicas e de regulação do marketing como temas relevantes da disciplina. A implantação das discussões sobre as consequências sociais do marketing em cursos de graduação tem o poder de captar a atenção dos estudantes para amplos temas sociais (RADFORD; HUNT; ANDRUS, 2015). Layton e Grossbart (2006) incluem as questões éticas como um tema de grande importância no macromarketing, o que interessaria como suporte aos debates a respeito dos "marqueteiros" e os entendimentos maléficos do marketing. 
Atrelados à questão social, surgiram alguns pontos com foco no acréscimo de uma abordagem crítica ao ensino de marketing para administradores, que também pode ser inclusa no escopo do macromarketing. $\mathrm{O}$ aspecto da localidade foi apontado pelo Professor 5:

Acho que macromarketing deveria se permitir uma agenda descolonizadora. Qual é a agenda Brasil disso? Quais são os impactos das ações de gestão em marketing no nosso país? Nós temos impactos que os americanos não têm, coisas que os americanos já resolveram, os europeus já resolveram, não resolveram e tal, populações marginalizadas. Então tem que ter uma agenda social e ambiental para pensar, acho que poderia ser uma disciplina transformadora de introdução ao marketing.

Outro aspecto levantado em uma perspectiva crítica para o ensino do marketing está relacionado à discussão a respeito do papel do Estado. Assim como Kotler (1986), que destaca a relevância dos Estados para as relações de mercado, o Professor 2 ressalta o papel do Estado como grande mediador do sistema de marketing:

Macromarketing resgata um ator muito relevante que é o governo. Qual o papel do Estado? Porque se a gente pensar o que marketing faz na concepção mainstream, tem impactos na sociedade. Vamos pensar em um primeiro momento que esse impacto seja positivo, contribui para o desenvolvimento do país, então, ele está associado a uma ideia de crescimento econômico e prosperidade. E se der problema, o que se faz? Como reconduzir marketing para uma forma que ele produza mais benefícios do que malefícios? (...) quando você extrapola essa ideia de que tem uma empresa e somente o consumidor e considera que tem outras instituições, tem o Estado que media isso, tem consumidores que reuniram forças para contestar essa prática de marketing da grande empresa. Então, tem o papel do IDEP, tem o papel do PROCON, Ministério Público. É engraçado que a literatura trivial não coloca esses atores, mas eles existem. Então o macromarketing acaba, de certa maneira, explodindo a ideia que você tem de relacionamento de mercado, incorporando outros atores.

Os professores entrevistados apontaram caminhos para a redução das deficiências do ensino de marketing e o aperfeiçoamento da forma- 
ção do administrador a partir da inclusão de temas de macromarketing em cursos de graduação. O Quadro 4 elenca a consolidação das possíveis contribuições do macromarketing para a diminuição das lacunas encontradas no ensino de marketing no Brasil e aumentar a relevância da disciplina. A expansão da compreensão do administrador a respeito do mercado, das atividades mercadológicas e suas consequências sociais e maior aproximação à realidade local, também, poderão contribuir para que o administrador possa acompanhar melhor as constantes mudanças no ambiente de negócios das organizações. 
Quadro 4 Resumo da Análise das Entrevistas

\begin{tabular}{|c|c|}
\hline $\begin{array}{l}\text { DEFICIÊNCIAS DO ENSINO DE } \\
\text { MARKETING EM CURSOS DE } \\
\text { ADMINISTRAÇÃO NO BRASIL }\end{array}$ & 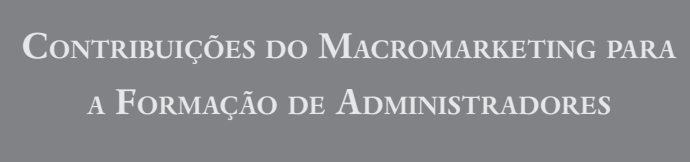 \\
\hline $\begin{array}{l}\text { Conceituação de Mercado } \\
\text { Deficiente }\end{array}$ & $\begin{array}{l}\text { Sistemas de Marketing - visão mais } \\
\text { complexa do mercado e do papel dos } \\
\text { agentes de Mercado (DIXON, 1984; } \\
\text { MEADE; NASON, 1991; LAYTON, 2007; } \\
\text { FLEMING et al., 2015) }\end{array}$ \\
\hline $\begin{array}{c}\text { Desconexão entre } \\
\text { Marketing e Sociedade }\end{array}$ & $\begin{array}{c}\text { Consequências sociais do marketing } \\
\text { (MOYER, 1974; BAGOZZI, 1977; NASON, } \\
\text { 1989) }\end{array}$ \\
\hline \multirow[t]{2}{*}{$\begin{array}{l}\text { Visão Acrítica - Distância de } \\
\text { Marketing da Perspectiva } \\
\text { Local }\end{array}$} & $\begin{array}{l}\text { Abordagem crítica e aproximação da } \\
\text { realidade local - maior complexidade } \\
\text { análise de suas características locais } \\
\text { (DHOLAKIA, 2012; FLEMING et } \\
\text { al., 2015; VASCONCELOS; COSTA; } \\
\text { CARVALHO, 2016) }\end{array}$ \\
\hline & $\begin{array}{l}\text { Consequências Sociais do marketing e } \\
\text { sistemas de marketing (MOYER, 1974; } \\
\text { NASON, 1989) }\end{array}$ \\
\hline $\begin{array}{l}\text { Crise de Relevância - } \\
\text { Marketing compreendido } \\
\text { de forma operacional } \\
\text { e reduzida, baseado no } \\
\text { estudo de relações entre } \\
\text { Unidades Produtoras e } \\
\text { Unidades Consumidoras }\end{array}$ & $\begin{array}{l}\text { Marketing entendido como maneira } \\
\text { de se compreender o mercado a partir } \\
\text { de uma visão sistêmica e que considera } \\
\text { uma ampla gama de agentes com papéis } \\
\text { distintos (MOYER, 1974; SHAPIRO; } \\
\text { TADAJEWSKI; SCHULTZ, 2009; } \\
\text { FLEMING et al., 2015; VASCONCELOS; } \\
\text { COSTA; CARVALHO, 2016) }\end{array}$ \\
\hline
\end{tabular}




\section{CONSIDERAÇÕES FINAIS}

No presente artigo, realizou-se uma discussão a respeito do ensino de marketing em cursos de graduação em administração brasileiros com a intenção de avaliar possíveis contribuições do macromarketing para a formação de administradores. A revisão da literatura e a análise das entrevistas com professores de marketing trouxeram à tona três lacunas do ensino de marketing associadas à superficialidade de tratamento do conceito de mercado, à desconexão da disciplina com questões sociais e perspectivas locais e à visão acrítica do campo. Tais lacunas contribuem para o despreparo do administrador em lidar com situações complexas dos mercados e são consequências de um posicionamento alinhado, exclusivamente, à perspectiva do micromarketing. A formação mercadológica do administrador deixa de lado relações sistêmicas entre os diversos agentes de marketing e os impactos desse sistema na sociedade.

Atualmente, o mundo globalizado apresenta um núcleo técnico que é organizado em termos de entradas, distribuição mundial, transformações e saídas, organizadas por meio de suprimentos globais. As redes de distribuição e as interfaces de marketing com a sociedade têm papel fundamental para o entendimento dos mercados (BANERJEE; CARTER; CLEGG, 2009). Assim, não cabe mais uma visão de marketing restrita à compreensão do comportamento dos consumidores ou aos interesses corporativos, mas uma perspectiva mais ampla a respeito das relações entre mercados, seus agentes e a sociedade.

Os achados desta pesquisa oferecem uma contraposição à visão gerencialista e incompleta, dominante no ensino de marketing. Verificou-se que o macromarketing pode contribuir para a melhoria da formação dos administradores a partir da inclusão das discussões a respeito de sistemas de marketing, das consequências sociais do marketing e da ampliação de uma abordagem crítica que permita ao profissional de marketing maior capacidade de avaliar o impacto das suas decisões na sociedade, como pleiteado por Holbrook (2005). 
Essa constatação faz questionar a razão pela qual os temas relacionados ao sistema de marketing e suas consequências na sociedade têm espaço reduzido na pesquisa e no ensino da disciplina. É preocupante a depreciação dos esforços direcionados às pesquisas de temas de macromarketing. Os acadêmicos interessados pela administração de marketing e pelos estudos de consumo não apenas estão deixando de ter uma visão mais ampla no tocante aos processos de marketing e consumo, como, também, estão cedendo espaço para pesquisadores das áreas de ciências humanas e de ciências sociais, que acabam realizando contribuições mais relevantes para a sociedade ao estudarem mercados (DHOLAKIA, 2012).

Espera-se que este artigo sirva como incentivo para que professores de marketing aprofundem seus conhecimentos a respeito do macromarketing e incluam temas dessa área em suas disciplinas. Também, pretende-se que os pesquisadores do campo se sintam, igualmente, motivados a direcionarem suas pesquisas para aspectos sistêmicos e sociais do marketing em busca de modelos teóricos que permitam compreensão mais abrangente das atividades do mercado. Acredita-se que esses esforços contribuiriam para o aumento da relevância da disciplina de marketing para os praticantes e fariam com que o marketing fosse reconhecido de forma mais positiva por acadêmicos e profissionais de outras áreas. 


\section{REFERÊNCIAS}

AKTOUF, O. Ensino de administração: por uma pedagogia da mudança. Organizações \& Sociedade, v. 12, n. 35, p. 151-160, 2005.

BACELLAR, F. C.; IKEDA, A. A. Evolução do ensino de marketing: um breve histórico. Organizações \& Sociedade, v. 18, n. 58, p. 487-511, 2011.

BACELLAR, F. C. T.; IKEDA, A. A.; ANGELO, M. Professores de marketing e a docência em ensino superior: revelando trajetórias e compreendendo perspectivas. In: ENANPAD, 29., 2005, Brasília. Anais... Rio de Janeiro: ANPAD, 2005.

BANERJEE, B.; CARTER, C.; CLEGG, S. Managing globalization. In: ALVESSON, M.; BRIDGMAN, T.; WILLMOTT, H. The Oxford Handbook of Critical Management Studies, Oxford: 2009. p.186-213.

BAGOZZI, R. P. Marketing at the societal level: theoretical issues and problems. In: SLATER, C. (Ed.). Macromarketing: distributive processes from a societal perspective. Boulder: University of Colorado, 1977. p. 6-51.

BARDIN, L. Análise de conteúdo. Lisboa: Edições 70, 1977.

BARROS, A. Antecedentes dos cursos superiores em administração brasileiros: as escolas de comércio e o curso superior em administração e finanças. Cadernos EBAPE.BR, v. 15, n. 1, p. 88-100, 2017.

BARROS, A.; ALCADIPANI, R.; BERTERO, C. O. A criação da graduação em Administração na UFRGS: a influência dos Estados Unidos e da FGV. In: COLÓQUIO DE EPISTEMOLOGIA, 5, 2015, Florianópolis. Anais... Florianópolis: [s.n], 2015.

BARTELS, R.; JENKINS, R. Macromarketing. Journal of Marketing, Chicago, v. 41, n. 4, p. 17-20, 1977.

BEHRENS, A. Para ensinar macroeconomia na graduação em administração. Administração: Ensino e Pesquisa, v. 14, n. 4, p. 707-724, 2013.

BORGES, G. F.; MAFRA, F. L. N. Ensino de contabilidade em cursos de graduação em administração: uma análise da percepção docente e discente em instituições de ensino superior de Minas Gerais. RACE: Revista de Administração, Contabilidade e Economia, v. 12, n. 3, p. 191-226, 2013.

BOSCHI, M. R.; BARROS, D. F.; SAUERBRONN, J. F. R. A introdução da disciplina de marketing no Brasil: "uma linguagem comum que nos une". Farol: revista de estudos organizacionais e sociedade, v. 3, n. 8, p. 857-924, 2016.

CASOTTI, L. O desafio de pensar e ensinar marketing. In: ENCONTRO ANUAL DA ASSOCIAÇÃO NACIONAL DE PÓS-GRADUAÇÃO EM ADMINISTRAÇÃO, 19., 1995, João Pessoa. Anais... João Pessoa: ANPAD, 1995. 
CONSELHO FEDERAL DE EDUCAÇÃO. Novo currículo mínimo do curso de graduação em administração. Brasília, Ago. 1993.

DHOLAKIA, N. Being critical in marketing studies: the imperative of macro perspectives. Journal of Macromarketing, v. 32, n. 2 p. 220-225, 2012.

DIXON, D. F. Macromarketing: a social systems perspective. Journal of Macromarketing, v. 4, n. 2, p. 4-17, 1984.

FARIA, A.; WENSLEY, R. A critical perspective on marketing strategy. In: ENCONTRO ANUAL DA ASSOCIAÇÃO NACIONAL DE PÓS-GRADUAÇÃO EM ADMINISTRAÇÃO, 29., 2005, Brasília, Anais... Brasília: ANPAD, 2005.

GRAEML, A. R.; PEINADO, J. O ensino de gestão de operações em cursos de graduação em administração do Brasil. Revista de Administração da Unimep, v. 11, n. 3, p. 119141, 2013.

HOLBROOK, M. Marketing miseducation and the MBA mind: bullshit happens. Marketing Education Review, v. 15, n. 3 p. 1-4, 2005.

HUNT, S. D. The three dichotomies model of marketing: an elaboration of issues. In: SLATER, C. C. (Ed.). Macromarketing: distributive processes from a societal perspective. Boulder: University of Colorado Press, 1977. p. 52-56.

HUNT, S. D.; BURNET, J. J. The macromarketing/micromarketing dicotomy: a taxonomical model. Journal of Marketing, v. 46, n. 3 p. 11-26, 1982.

KOTLER, P. Megamarketing. Harvard Business Review, v. 64, n. 3, p. 117-124, 1986.

FLEMING, M. C. et al. Explorando a matriz social de um sistema de marketing: o caso Serra Pelada. Revista Alcance, v. 22, n. 4, p. 586-601, 2015.

LAYTON, R. A. Marketing systems - a core Macromarketing concept. Journal of Macromarketing, v. 27, n. 3, p. 227-242, 2007.

LAYTON, R. A.; GROSSBART, S. Macromarketing: past, present, and possible future. Journal of Macromarketing, v. 26, n. 2, p. 193-2013, 2006.

LISBOA, J. A. Aula de comércio. Revista do IHGB, n. 208, p. 172-185, 1950.

LOURENÇO, C. D. S.; TONELLI, D. F.; MAFRA, F. L. N. Reconciliação entre o econômico e o social: um desafio para o ensino de Administração. In: ENCONTRO DE ENSINO E PESQUISA EM ADMINISTRAÇÃO E CONTABILIDADE DA ANPAD. 2. Curitiba. Anais..., Curitiba: ANPAD, 2009.

LOURENÇO, C. D. S. et al. Produção científica brasileira sobre ensino de administração: 1997-2010. Revista Pensamento Contemporâneo em Administração, v. 6, n. 1, p. 4-22, 2012.

MEADE, W. K.; NASON, R. W. Toward a unified theory of macromarketing: a system theoretic approach. Journal of Macromarketing, v. 11, n. 2, p. 72-82, 1991. 
MENDONÇA, M. C. Aula de Comércio. Rio de Janeiro: Xerox do Brasil, 1982.

MOYER. R. Macro Marketing: uma perspectiva social. Rio de Janeiro: Editora Americana, 1974.

NASON, R. W. The social consequences of marketing: macromarketing and public policy. Journal of Public Policy \& Marketing, v. 8, n. 2, p. 242-251, 1989.

NICOLINI, A. Qual será o futuro das fábricas de administradores? RAE: revista de administração de empresas, v. 43, n. 2, p. 44-54, 2003.

OLIVEIRA, A. L.; LOURENÇO, C. D. S.; CASTRO, C. C. Ensino de administração nos EUA e no Brasil: uma análise histórica. Pretexto, v.16, n.1, p.11-22, 2015.

OLIVEIRA, F. B.; SAUERBRONN, F. F. Trajetória, desafios e tendências no ensino superior de administração e administração pública no Brasil: uma breve contribuição. RAP: Revista de Administração Pública, Edição Especial Comemorativa, p. 149-170, 2007.

O'SHAUGHNESSY, J. Temerarious directions for marketing. European Journal of Marketing, v. 31, n. 9/10, p. 677-705, 1997.

PIERCY, N. Research in marketing: teasing with trivia or risking relevance? European Journal of Marketing, v. 36, n. 3, p. 350-363, 2002.

PRESTES MOTTA, F. C. A questão da formação do administrador. RAE: Revista de Administração de Empresas, v. 23, n. 4, p. 53-55, 1983.

RADFORD, S. K; HUNT, D. M.; ANDRUS, D. Experimental learning projects: a pedagogical path to macromarketing education. Journal of Macromarketing, v. 35, n. 4, p. 466-472, 2015.

RODRIGUES, E. R.; MATIAS, A. B. Ensino em administração: proposta do conteúdo programático de finanças. Administração: Ensino e Pesquisa, v. 17, n. 2, p. 245-274, 2016.

SAUERBRONN, J. F. R. Diga-me o que publicas e te direi quem és: perspectivas e resistências na publicação da produção de conhecimento em marketing. Revista de Negócios, v. 18, n. 1, p. 42-52, 2013.

SCHMITZ, L. et al. Limitações e dificuldades na utilização da abordagem experiencial no ensino de gerenciamento de projetos em um curso de graduação em administração. Administração: Ensino e Pesquisa, v. 16, n. 3, p. 537-569, 2015.

SHAPIRO, S. J. Marketing Terms: definitions, explanations, and/or aspects. 3.ed. West Long Beach: S-M-C Pub., 1973.

SHAPIRO, S. J. A JMM-based macromarketing doctoral level reading list. Journal of Macromarketing, v. 26, n. 2, p. 250-255, 2006.

SHAPIRO, S. J. Macromarketing teaching materials: a forty-year retrospective. Journal of Macromarketing, v. 32, n. 4, p. 412-416, 2012. 
SHAPIRO, S. J.; TADAJEWSKI, M.; SCHULTZ, C. J. Macromarketing. London: Sage, 2009.

SHAW, E. H. Revisiting and revising Alderson's formula to measure the productivity of the aggregate marketing system. Marketing Theory, v. 10, n. 4, p. 347-367, 2010.

SHETH, J. N.; GARDNER, D. M.; GARRET, D. E. Marketing Theory: evolution and evaluation. New York, John Wiley \& Sons, 1988.

SOUZA, Â. M.; SARAIVA, L. A. S. Práticas e desafios do ensino de empreendedorismo na graduação. Gestão \& Regionalidade, v. 26, n. 78, p. 64-77, 2010.

TADAJEWSKI, M. Quaker travels, fellow traveller? Wroe Alderson's visit to Russia during the cold war. Journal of Macromarketing, v. 29, n. 3, p. 303-324, 2009.

TAMILIA. R. D.; VEILLEUX. S. Teaching Macromarketing at the Undergraduate Level: A Needed Reality in the 21ST Century. ASAC, Otawa. v. 28, n. 1, p. 39-57. 2007.

VASCONCELOS, M. F.; COSTA, F. J.; CARVALHO, D. T. Educação em marketing: visões e práticas de domesticação no contexto nordestino. REUNIR: Revista de Administração, Contabilidade e Sustentabilidade, v. 6, n. 1, p. 107-117, 2016.

WHITE, P. D.; EMERY, D. R. Simplifying Macromarketing: the need for improved understanding and the implications for research planning and execution. In: JAIN, Subhash C. (Ed.) Research in Marketing: dialogues and directions. Chicago: AMA, 1978.

WOOLISCROFT, B.; TAMILIA, R. D.; SHAPIRO, S. J. A Twenty-First Century Guide to Aldersonian Marketing Thought. New York: Springer, 2006. 


\section{ANEXO A - ROTEIRO DE ENTREVISTAS}

\section{PARTE 1 - TRAJETÓRIA COMO PROFESSOR}

- Há quantos anos você leciona? Há quanto tempo leciona marketing?

- Como você se tornou professor de marketing? Como foi lecionar marketing?

- Em qual(is) instituição(ões) de ensino você trabalha(ou)?

- Quais disciplinas de marketing você leciona e lecionou? Alguma dessas apresentava alguma conexão com o macromarketing?

- Qual sua familiaridade com os temas discutidos dentro do campo do macromarketing?

- Quando ouviu falar sobre macromarketing pela primeira vez? Onde? Por quê?

\section{PARTE 2 - PENSAMENTO A RESPEITO DO ENSINO DE MARKETING}

- Para você, quais seriam os objetivos do ensino de marketing nos cursos de administração no Brasil? Estes objetivos estão adequados? Por que $\operatorname{sim} /$ não?

- O que você pensa a respeito do ensino de marketing nos cursos de administração e marketing brasileiros?

- Como a disciplina de marketing se conecta com o restante do curso de administração e marketing no Brasil? Essa conexão é suficiente/"correta"?

- Quais disciplinas de marketing propiciam uma abordagem mais completa dos temas de marketing?

- Como você vê o papel do professor na introdução de pontos de vista mais complexos na disciplina de marketing?

- O que você pensa sobre o espaço dado aos diversos temas de marketing em periódicos e congressos no país?

- Como você vê a influência das pesquisas acadêmicas em marketing no ensino da disciplina no Brasil?

- Como você vê a influência de teorias externas na construção da disciplina de marketing no Brasil? 
- Como você vê a influência de material didático produzido fora do país na construção da disciplina de marketing no Brasil?

- Para você, qual o papel da prática de marketing para a sociedade?

- Você vê alguma lacuna no ensino de marketing nos cursos de administração e marketing brasileiros? Qual(is)?

- Você identifica lacunas na prática de marketing no Brasil? Quais?

- Você identifica lacunas na compreensão dos mercados no Brasil? Quais?

- Como a formação do professor se relaciona com o conteúdo que é lecionado?

PARTE 3 - ASPECTOS MAIS ESPECÍFICOS DO MACROMARKETING

- O que é macromarketing para você?

- Como você definiria o campo do macromarketing?

- Qual pode ser a contribuição dos temas de macromarketing para o ensino de administração e marketing no Brasil?

- Qual pode ser a contribuição dos temas de macromarketing para a formação dos estudantes no Brasil?

- Que temas de macromarketing você julga importantes para o ensino de marketing?

- O que você gostaria de acrescentar a respeito do ensino de marketing e o macromarketing? 


\section{DADOS DOS AUTORES}

\section{RODOLFO PERES BERARDINELLI $r$ _berardinelli@yahoo.com.br}

\section{Mestre em Administração pela Unigranrio}

Instituição de vinculação: Universidade do Grande Rio

Rio de Janeiro/RJ - Brasil

Áreas de interesse em pesquisa: Marketing, Macromarketing, Comunicação, Cultura e Tecnologia.

* Rua da Lapa, 86-9 andar Lapa Rio de Janeiro/RJ 20021-180

\section{JOÃO FELIPE RAMMELT SAUERBRONN joao.sauerbronn@unigranrio.edu.br}

Doutor em Administração pela EBAPE/FGV-RJ

Instituição de vinculação: Universidade do Grande Rio

Rio de Janeiro/RJ - Brasil

Áreas de interesse em pesquisa: Cultura e Consumo, Macromarketing, Pesquisa

Qualitativa. 